\title{
Impurity influence on normal grain growth in the GISP2 ice core, Greenland
}

\author{
R. B. Alley and G. A. Woods \\ Earth System Science Center and Department of Geosciences, The Pennsylvania State University, University Park, \\ Pennsylvania 16802, U.S.A.
}

\begin{abstract}
Intercept analysis of approximately bi-yearly vertical thin sections from the upper part of the GISP2 ice core, central Greenland, shows that grain-size ranges increase with increasing age. This demonstrates that something in the ice affects grain-growth rates, and that grain-size cannot be used directly in paleothermometry as has been proposed. Correlation of grain-growth rates to chemical and isotopic data indicates slower growth in ice with higher impurity concentrations, and especially slow growth in "forest-fire" layers containing abundant ammonium; however, the impurity/grain-growth relations are quite noisy. Little correlation is found between growth rate and isotopic composition of ice.
\end{abstract}

\section{INTRODUCTION}

In the isothermal firn and shallow ice of cold ice sheets, grain growth is driven by the energy and curvature of grain boundaries ("soap-bubble growth"), and average grain cross-sectional area $\bar{A}$ increases linearly with age $t$ according to

$$
\bar{A}=\bar{A}_{0}+K t
$$

where $\bar{A}_{0}$ is the initial average grain cross-sectional area and $K$ shows an Arrhenius dependence on temperature and may depend on other factors (Gow, 1969). Unusually high soluble and insoluble impurity concentrations contribute to slow growth rates in cold ice (reduced $K$; Gow and Williamson, 1976).

Ice from the Wisconsinan (the last glacial period) in cores from Dome C and Vostok, Antarctica, falls in the depth range of "soap-bubble" grain growth but exhibits anomalously small grain-sizes compared to overlying Holocene ice even after correction for their different temperature histories using the Arrhenius dependence of grain-growth rate on temperature (Duval and Lorius, 1980; Petit and others, 1987). Possible explanations for these small grain-sizies include reduced $K$ in Equation (1) owing to drag effects of the higher (but still quite low) impurity concentrations in Wisconsinan ice (Alley and others, 1986a, b) or owing to a "memory" of the lower Wisconsinan firnification temperature imprinted on the ice structure at densities less than $550 \mathrm{~kg} \mathrm{~m}^{-3}$ (roughly the upper $10-20 \mathrm{~m}$ ) and then "quenched" (Petit and others, 1987).

Because of the close correlation of firnification temperature and impurity loading in Wisconsinan ice from central East Antarctica, the field data do not allow separation of these potential controls. Various physical arguments have been presented (Alley and others, 1988; Petit and others, 1988; Paterson, 1991). In particular, Duval and Lorius (1980) and Petit and others (1987, 1988) argued that the soluble and insoluble impurity concentrations of Holocene and Wisconsinan ice from inland sites in Antarctica and Greenland are too low to have affected grain-growth rates measurably. In contrast, Alley and others (1986a, b, 1988) argued that drag effects from a given impurity can vary by orders of magnitude depending on the state of the impurity in the ice, and that significant impurity-drag effects are probable in ice-sheet ice for likely impurity distributions.

Jouzel and others (1987) and Petit and others (1987) used the assumed relation between firnification temperature and growth rate as a paleothermometer for Antarctic cores. If impurity effects are significant or dominant, or if a temperature "memory" does not affect growth rates, then grain-size is not an appropriate paleothermometer.

Seasonal cycles allow a partial test of this argument. All ice from a depositional year in the upper part of an ice sheet has experienced the same strain history, and the same diagenetic-temperature history below the upper meter or two, but seasonal variations in impurity loadings are as large as, or larger than, the few-fold differences between Wisconsinan and Holocene ice from central East Antarctica.

If grain-growth rates within a year differ, then something other than a memory of diagenetic temperature is affecting the growth rates, and grain-size cannot be used directly in paleothermometry. Correlation between growth rate and impurity loading then would suggest impurity-drag effects, and correlation between growth rate and isotopic composition might suggest some memory of depositional conditions or diagenesis in the first year or so, or a true isotopic effect. Notice, however, that such a study cannot directly address the Petit and 
others (1987) hypothesis of existence of a temperature memory, because all of the samples will have experienced essentially the same diagenetic-temperature history as they approached the hypothesized "quenching" level in the firn; we can only test whether effects other than a temperature memory are active.

\section{METHODS}

The GISP2 ice core was drilled during the summers of $1989-93$ at $72.6^{\circ} \mathrm{N}, 38.5^{\circ} \mathrm{W}, 3200 \mathrm{~m}$ elevation, $28 \mathrm{~km}$ west of the summit of the Greenland ice sheet, by the Polar Ice Coring Office. Mean annual $(20 \mathrm{~m})$ temperature is about $-31^{\circ} \mathrm{C}$, and accumulation is about $240 \mathrm{~mm}$ ice year ${ }^{-1}$ (Alley and Koci, 1990; Alley and others, 1993). Dating used here is from Alley and others (1993) and Meese and others (1994). A full suite of physicalproperties studies was conducted on the core, including measurement of $c$-axis fabrics and grain-sizes on horizontal and $10 \mathrm{~cm}$ vertical thin sections, densities and sonic velocities (Gow and others, 1993; Anandakrishnan and others, 1995; unpublished information from A.J. Gow, 1996). Here, we focus on a single experiment to address controls on normal grain growth.

Typically within days of retrieving cores, vertical thin sections were cut along the sides of selected core sections using a band-saw. (For the region of very brittle ice between 680 and $1370 \mathrm{~m}$, some sections were cut immediately and some after a year of storage at the GISP2 site at $-30^{\circ} \mathrm{C}$ to allow this brittle ice to relax; no differences in the grain structure were observed after the storage, except that the ice fractured into small pieces when worked soon after cores were retrieved, but was easier to work with after storage.) After the back of each ice sample was sanded flat, the ice was affixed to a glass plate using either cyanoacrylate adhesive or slight warming of the plate followed by "freezing-on" (we observed no differences in grain structure between these two techniques, but the cyanoacrylate gave sections that were easier to observe because it avoided the "bubbledout" air trapped between the ice and glass of some deeper frozen-on samples). The ice then was microtomed to an appropriate thickness (roughly $0.5 \mathrm{~mm}$ ) for petrographic study. The samples were photographed between crossed polarizers. Sections as long as $18 \mathrm{~cm}$ were prepared, with use of consecutive sections to extend continuous coverage to $50 \mathrm{~cm}$ in many regions. Sample widths typically were 8-10 cm.

Grain-sizes were measured using the mean-intercept technique. In this, a test line is drawn on the section, and the length of line divided by the number of grains crossed gives the grain-size. From stereological experience and theory (see Underwood, 1970, ch.4; Alley, 1987a, b), as long as the grain shapes do not change greatly with depth, any measure of the mean grain cross-sectional area will be related to the square of the mean intercept length by a constant geometrical factor of order 1 which corrects for the section effect (many grains are cut near an edge rather than through the center; Gow, 1969) and for the geometry of the sampling (see Underwood, 1970, tables 4.1 and 4.2). We used the geometrical factor for monosized spheres following Underwood (1970), as discussed in Alley (1987b). Grain cross-sections remained nearly equant and convex throughout the upper part of the core that we consider in detail, although with a slight tendency to become flattened with elongation parallel to the ice-sheet surface.

Use of mean intercept rather than some areal measure (e.g. Gow, 1969; Alley, 1987a, b) is preferred here because of the ease of measurement and the high stratigraphic resolution. Ambiguity would be introduced to this study if we were forced to choose whether a given grain overlapping a stratigraphic boundary "belonged" to one of the two layers or to both. A layer-parallel test line can always be assigned to a layer, and measures the grain-size in that layer. Previous use of this mean-intercept technique in glaciology includes that of Thorsteinsson and others (1995; see also Alley, 1987a, b).

Most of the observations were made by one of us (G.A.W.) and are detailed in Woods (1994). We measured grain-size within individual stratigraphic layers by using horizontal test lines only. We placed a test line typically every $2 \mathrm{~mm}$ along the core, and test lines sampled typically 30 grains or more. Thus, a sample of 100 grain crossings is obtained typically every $6-8 \mathrm{~mm}$ along the core. Grain-sizes were averaged over $2-3 \mathrm{~cm}$ for comparison to chemical and isotopic data, as described below.

Grain-growth studies such as Gow (1969) and Duval and Lorius (1980) are based on the average grain-size, $\bar{A}$, in a sample containing a wide range of grain-sizes. Measurement of a large enough number of grains is required to allow accurate determination of the average grain-size, as discussed in Underwood (1970, p. 12-18; see also summary in Alley, 1987b, p.66-68). Typically, average grain-sizes based on measurement of a few tens to a few hundreds of grains are sufficient to determine $\bar{A}$, within a few per cent or less.

Major ions and cations were measured by the Glacier Research Group, University of New Hampshire (e.g. Mayewski and others, 1993). Impurity concentrations are similar to or a little lower than typical values cited by Petit and others $(1987,1988)$ for other inland sites (e.g. a few ppb to a few tens of ppb $\mathrm{Na}^{+}$for GISP2, vs 20$40 \mathrm{ppb} \mathrm{Na}^{+}$, cited by Petit and others). Stable-isotopic compositions were measured by the Quaternary Isotope Laboratory, University of Washington, and at the Institute for Arctic and Alpine Research, University of Colorado (Grootes and others, 1993). Vertical sampling intervals for chemistry and istopes were typically $2-3 \mathrm{~cm}$.

\section{RESULTS}

Grain-size data (mean intercept) are shown in Figure 1 for the entire core (Woods, 1994). Woods (1994) identified four grain-growth regimes:

(1) Grain-size increase consistent with Equation (1), the linear area/age model of Gow (1969), in the nearly isothermal ice of the upper $700 \mathrm{~m}(0-3200$ years old; see Fig. 2 and Woods, 1994).

(2) Constant grain-size from 700 to $1678 \mathrm{~m}$ depth (320011600 years, with 11600 years being the end of the Younger Dryas cold event). 


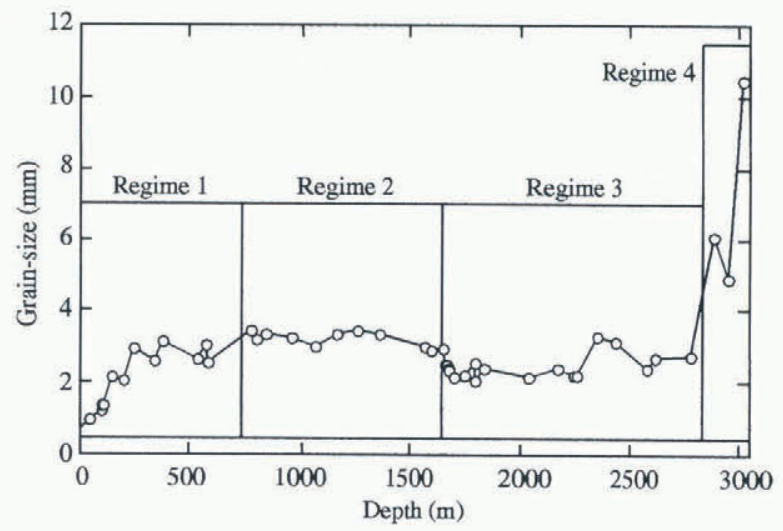

Fig. 1. Mean horizontal intercept of grains vs depth in the GISP2 ice core, from Woods (1994). The four graingrowth regimes are described in the lext and in Woods (1994), and overlie fine-grained silty ice at the bed. We plol mean intercept rather than cross-sectional area to allow better display of the coarse grains near the bed.

(3) Often smaller grain-size but with variations that correlate directly with isotopic composition deposition temperature) and inversely with impurity loadings in and before the Younger Dryas event.

(4) Very large grains in warmer ice near the bed (see also Gow and others, 1993; Thorsteinsson and others, 1995; basal temperatures reach as high as $-9^{\circ} \mathrm{C}$ near the bed; Cuffey and others, 1995).

These four zones of clean glacier ice overlie very finegrained, visibly silty basal ice. The boundary between regimes 1 and 2 probably is gradual, and that between zones 3 and 4 appears interfingered (see also Thorsteinsson and others, 1995).

Woods (1994) interpreted the large grain-sizes in his deepest zone as representing annealing associated with high basal temperatures Gow and Williamson, 1976; Budd and Jacka, 1989), the ice-age zone as reflecting some impurity or other effects on grain-growth or grainsubdivision rates (Langway and others, 1988; Paterson, 1991; Thorsteinsson and others, 1995), the constant grain-sizes in the older part of the Holocene as representing grain subdivision by polygonization at the same rate that grains are consumed by normal grain growth (Alley and others, 1995) and the upper part as representing normal "soap-bubble" grain growth. In the deeper zones, small grain-sizes may indicate slow grain growth or rapid grain subdivision, so we restrict our attention to the upper few hundred meters where grain growth occurs without grain subdivision.

Figure 2 shows a more detailed view of data from this region of normal grain growth (regime 1). Notice from Figure 1 that grain growth continues to about $700 \mathrm{~m}$ or 3200 years; by omitting from Figure 2 samples in the older part of regime 1, it might appear that grain growth stops somewhat earlier because of fluctuations in the data. The transition from regime 1 to regime 2 does appear gradual, however, as polygonization becomes more important with increasing depth. We believe, based on inspection of the samples for strain shadows, etc., that our analyses in regime 1 are confined to ice above depths of significant polygonization.

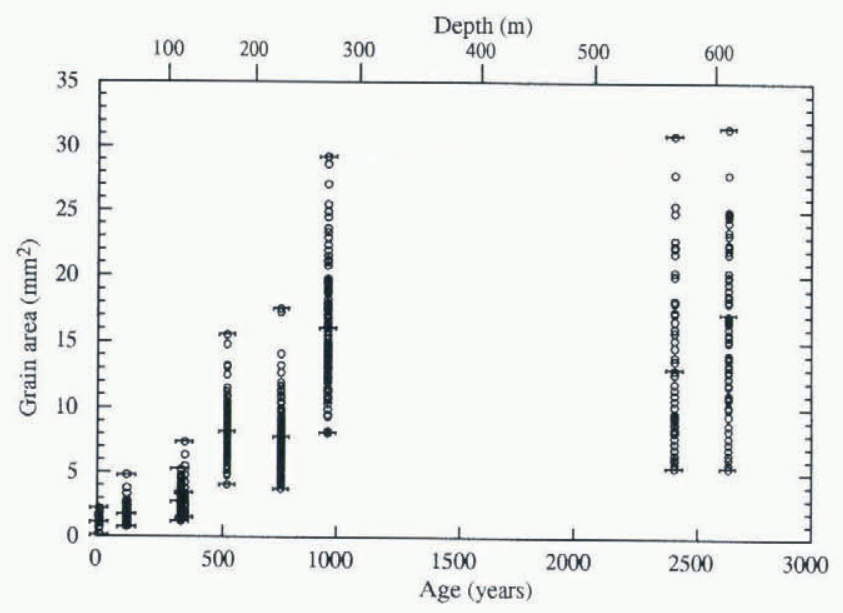

Fig. 2. Mean grain cross-sectional area os age in the normal-grain-growth zone (regime 1) of the GISP2 core. The average grain-size, $\bar{A}$, for each $8-10 \mathrm{~cm}$ long test line is shown as a point; all test lines (roughly 250 per sample) in each approximately 2 year thin section are shown al the same age. Regression lines are shown for all of the dala, and for the smallest and the largest average grain-sizes in each 2 year interval. The next-deeper 2 year thin sections, at the top of regime 2, are somewhat coarser than those shown here (see Fig. 1).

Figure 2 shows that the average grain-size (area) and the range of grain-sizes in a sample increase with increasing age, and thus also with depth. Each point represents a test line of roughly $10 \mathrm{~cm}$ or 30 grains. Various other plotting conventions (for example, averaging all test lines in $3 \mathrm{~cm}$ lengths along the core, or roughly 500 grains) yield a similar result, so this is not a sampling artifact. Within ice from a 2 year period, the range between the average grain-sizes in the coarsestgrained and finest-grained layers increases with increasing depth and age.

A clear difficulty in estimating average grain-growth rate from average grain-size in a layer is that one cannot tell whether a given layer in a deeper sample began as a coarse-grained, medium-grained or fine-grained layer near the surface. The two youngest samples shown in Figure 2 are from snow pits in the upper $2 \mathrm{~m}$ (upper 3 years; density $\approx 330 \mathrm{~kg} \mathrm{~m}^{-3}$ ) and from $39.5-40 \mathrm{~m}$ depth in the core (density $\approx 690 \mathrm{~kg} \mathrm{~m}^{-3}$ ); they thus bracket the end of rapid firnification and the depth at which the "temperature memory" is acquired in the Petit and others $\left(1987,1988\right.$ ) model (density $\approx 550 \mathrm{~kg} \mathrm{~m}^{-3}$, achieved at $\approx 15 \mathrm{~m}$ depth). The average grain-size in these youngest samples is small compared to the older ones in Figure 2, and the range of average grain-sizes in the youngest samples is narrow. We thus do not introduce great error by using the intercept of the regression line through all the data in Figure 2 as the initial grain-size, $\bar{A}_{0}$, in calculating grain-growth rates for deeper samples, and we have done so in subsequent calculations.

The uncertainty in growth rate introduced by this lack of knowledge of starting grain-size can be assessed by drawing a line from any point of interest to the top and to the bottom of the array of grain-sizes for the two shallowest samples. This uncertainty clearly decreases as age, depth and grain-size increase, and is nearly 
insignificant for the deeper samples in regime 1, which is why we concentrated sampling in the deeper part. No large climatic changes have occurred through this time (e.g. Grootes and others, 1993; Meese and others, 1994), so the starting grain-size is unlikely to have changed significantly.

We formed correlation tables between grain-growth rate, stable-isotopic composition, concentrations of soluble major ions $\mathrm{Mg}^{2+}, \mathrm{Ca}^{2+}, \mathrm{Na}^{+}, \mathrm{K}^{+}, \mathrm{Cl}, \mathrm{NH}_{4}{ }^{+}$, $\mathrm{NO}_{3}{ }^{-}, \mathrm{SO}_{4}{ }^{2-}$ ), and total soluble ions (both by weight and by number of molecules) for those thin sections for which we have complete chemical and isotopic data. Examples are shown in Woods (1994) and summarized in Figure 3.

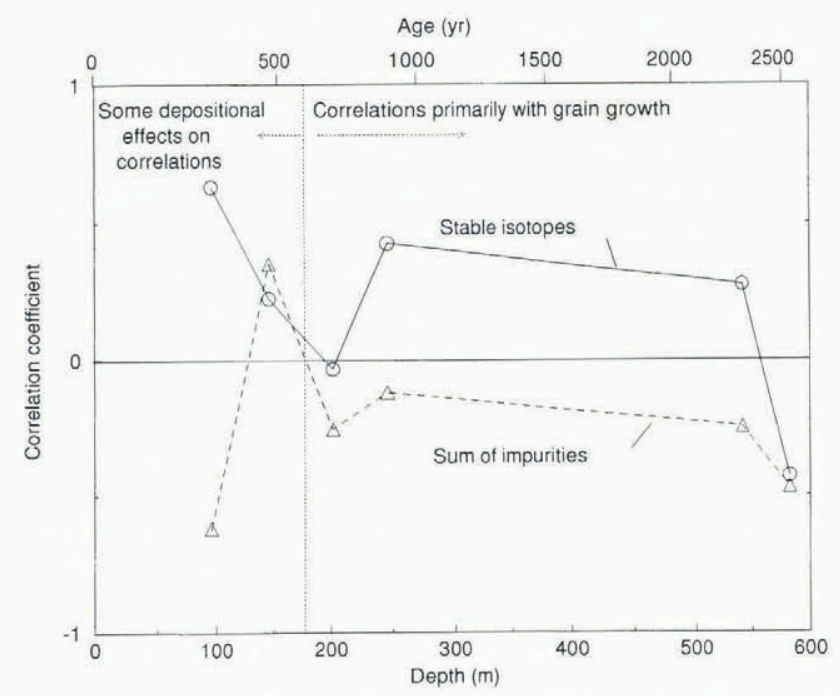

Fig. 3. Correlation coefficients of grain-growth rate to weight of soluble impurities, and to stable-isotopic composition, plotted against depth for those samples from Figure 2 for which we have complete chemical and isotopic data. Shallow samples include some information from deposition as well as grain growth; deeper samples have experienced sufficient grain growth to lose most of the depositional information. The positive correlation to isotopes in the shallow samples reflects the formation of coarse grains in isotopically heavy summer snow during its first year; the relation to impurities is noisy at this age. With increasing age, the correlation to isotopic ratio disappears but an inverse correlation to impurity loading develops, suggesting impurity control of growth rate.

\section{Our main observations are:}

(1) The range of average grain-sizes, $\bar{A}$, of layers millimeters to centimeters thick within a 2 year $(50 \mathrm{~cm})$ thin section increases with increasing depth, showing that grain-growth rates differ substantially between adjacent layers in the core (different $K$ despite the same in situ temperature) (Fig. 2).

(2) Negative correlations between grain-growth rate and concentration of a soluble impurity are obtained more frequently than would be expected by chance, although the results are quite "noisy" (Fig. 3; Woods, 1994). For example, to have all four of the deeper samples exhibit a negative correlation between growth rate and impurity loading as observed would occur only once in 16 tests if the distributions are random, and other such negative correlations with other measures of impurity loading increase the probability that non-random effects are present.

(3) Consistent correlations between grain-growth rates and isotopic compositions are not obtained.

(4) "Forest-fire layers" - those centimeter-scale layers in which ammonium concentration is high, electrical conductivity is low, the ice appears cloudy or faintly greenish with small bubbles, and in which carbon black has been found when sought, showing significant fallout from forestfire smoke plumes-have very slow grain growth (Legrand and others, 1992; Whitlow and others, 1994; Chýlek and others, 1995; Taylor and others, 1996; see Fig. 4). We have observed frequently the correlation between electrical-conductivity lows and small grain-sizes (see Woods, 1994, figs 5.3 and 5.4, for example), with sufficient confirmation of the conductivity-low/ammonium-high relation (Taylor and others, 1996) to be convincing.

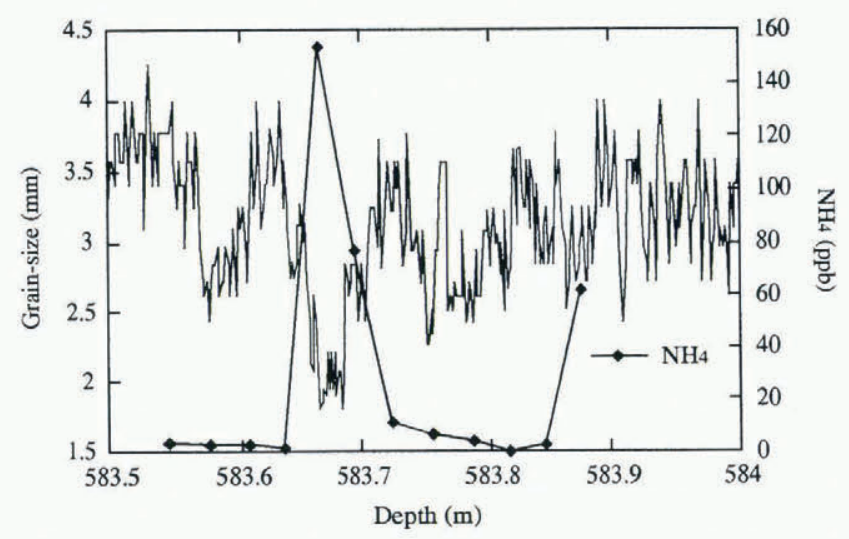

Fig. 4. Mean grain intercept against ammonium concentration across a "forest-fire" spike in a thin section from 583.5-584 $\mathrm{m}$ depth (approximately 2600 years age).

The correlation of fine grains to high ammonium near $583.68 \mathrm{~m}$ depth is clear. These layers showing the chemical signal of forest-fire fallout are readily identified by electrical conductivity (Taylor and others, 1996), and we have seen this correlation with fine grain-sizes in other layers.

\section{DISCUSSION}

The average grain-growth rate obtained by regression through the plot in Figure 2, for the GISP2 site temperature of $-31^{\circ} \mathrm{C}$, falls close to the activation-energy plot for other sites in Greenland and Antarctica when the data are reduced in a consistent way (Gow, 1969; Woods, 1994). This indicates that our data from vertical thin sections yield the same basic relations as data from other sites, as expected.

The data in Figure 2 are from thin sections $40-50 \mathrm{~cm}$ in length, and typically covering 2 years each. The shallowest data include discrete samples collected over $2 \mathrm{~m}$ depth (3 years) in two snow pits, with sampling designed to obtain the most extreme grain-sizes present. All of the ice within a sample has experienced the same temperature history after its first year or two, and the same strain history (cumulative vertical strain in the upper $600 \mathrm{~m}$ of the ice sheet of only about $20 \%$ ), yet the 
grain-growth rates differ as shown in Figure 2. We argue that this demonstrates that something in the ice affects grain growth $K$ in Equation (1) depends on some factor or factors other than in situ temperature).

Because all of the ice in regime 1 has experienced essentially the same firnification temperature, our data cannot directly address the Petit and others (1987, 1988) hypothesis of a diagenetic-temperature memory effect on $K$; our data would allow both impurities and diagenetic temperature to affect grain-growth rates. We still believe that physical arguments presented elsewhere do not allow this, but the reader must assess those arguments independently.) We note that the lack of significant correlation of grain-growth rate to isotopic composition allows us to exclude depositional temperature or true isotopic effects as strong controls on grain-growth rate.

The negative correlations between grain-growth rates and impurity concentrations are quite noisy and variable. This may be due partly to sampling constraints; even the high-resolution chemical and isotopic sampling used here did not resolve all of the layering in the ice core. This is exacerbated by the difficulty of precisely registering thin sections to chemical samples. We do not believe that this is sufficient to explain the noisiness, however. The impurity-drag hypothesis is very poorly quantified. As outlined by Alley and others (1986a,b), the impurity-drag effect changes by orders of magnitude for plausible changes in impurity distributions among liquid or solid second phases and dissolved species (Wolff and others, 1988). The state of impurities in the ice is poorly known, probably varies between layers and may vary over time (Wolff, 1996).

The fine-grained "forest-fire" layers suggest that we can learn more about the controls of grain growth. We cannot tell, of course, what chemical or particulate species in the forest-fire layers controls the grain growth, as several properties seem to vary together. The strong ammonium signal, and the observation that ammonium has a significant effect on ice in a variety of ways (e.g. Gross and others, 1978), lead us to suspect ammonium as an active player. Note that if this is true, there may be threshold effects or other species involved; ammonium variations do not explain all grain-size variations, as shown in Figure 4 and in other data.

Much further work is needed. The six data points in Figure 4, representing detailed isotopic and chemical studies and thin sections covering 12 years and counting exercise by Woods (1994) involving approximately 50000 intersections between test lines and grains, are still not sufficient to reveal all of the controls on grain growth. Other sites with greater total grain growth in the "soapbubble" or normal regime might give more-definitive results. Nonetheless, we conclude that something in the ice does affect grain-growth rates, so that grain-size is not a useful paleothermometer. Impurity drag seems most likely, and is supported by correlation analysis, even at the very low concentrations of impurities in Holocene ice from central Greenland.

\section{ACKNOWLEDGEMENTS}

We thank K. Cuffey, B. Elder, J. Fitzpatrick, A.J. Gow, G. Jablunovsky, W. Kapsner, D. Meese and G. Zielinski for assistance in sampling, P. Mayewski and co-workers for unpublished chemical data, J. White, B. Vaughn and co-workers for unpublished deuterium-isotopic data, P. Grootes and co-workers for unpublished oxygen-isotopic data, A.J. Gow, D. Meese and two anonymous reviewers for helpful suggestions, the GISP2 Science Management Office, the Polar Ice Coring Office, the 109th New York Air National Guard, the National Ice Core Lab and assorted GISP2 colleagues for assistance and logistical support, and the National Science Foundation Office of Polar Programs for financial support; some funding also was provided by the D. and L. Packard Foundation and NASA-EOS.

\section{REFERENCES}

Alley, R. B. 1987a. Texture of polar firn for remote sensing. Ann. Glaciol., 9, $1-4$.

Alley, R. B. 1987b. Transformations in polar firn. Ph.D. thesis, University of Wisconsin-Madison.

Alley, R.B. and B. R. Koci. 1990. Recent warming in central Greenland? Ann. Glaciol., 14, 6-8.

Alley, R. B., J. H. Perepezko and C. R. Bentley. 1986a. Grain growth in polar ice: I. Theory. J. Glaciol., 32 (112), 415-424.

Alley, R. B., J.H. Perepezko and C. R. Bentley. 1986b. Grain growth in polar ice: II. Application. J. Glaciol., 32 112$)$, 425-433.

Alley, R. B., J. H. Perepezko and C. R. Bentley. 1988. Long-term climate changes from crystal growth. Nature, 332 6165), 592-593.

Alley, R.B. and 10 others. 1993. Abrupt increase in Greenland snow accumulation at the end of the Younger Dryas event. Nature, $362(6420), 527-529$.

Alley, R. B., A.J. Gow and D. A. Meese. 1995. Mapping $c$-axis fabrics to study physical processes in ice. J. Glaciol., 41 (137), 197-203.

Anandakrishnan, S., J.J. Fitzpatrick, R. B. Alley, A.J. Gow and D. A. Meese. 1994. Shear-wave detection of asymmetric $c$-axis fabrics in the GISP2 ice core, Greenland. F. Glaciol., 40 (136), 491-496.

Budd, W. F. and T. H. Jacka. 1989. A review of ice rheology for ice sheet modelling. Cold Reg. Sci. Technol., 16 2, 107-144.

Chýlek, P., B. Johnson, P. A. Damiano, K. C. Taylor and P. Clement. 1995. Biomass burning record and black carbon in the GISP2 ice core. Geophys. Res. Lett., 22 (2), 8992.

Cuffey, K. M., G. D. Clow, R. B. Alley, M. Stuiver, E. D. Waddington and R.W. Saltus. 1995. Large Arctic temperature change at the Wisconsin-Holocene glacial transition. Science, 270 5235), 455458.

Duval, P. and C. Lorius. 1980. Crystal size and climatic record down to the last ice age from Antarctic ice. Earth Planet. Sci. Lett., 48 1), 59 64.

Gow, A.J. 1969. On the rates of growth of grains and crystals in South Polar firn. J. Glaciol., 8 (53), 241-252.

Gow, A.J. and T. Williamson. 1976. Rheological implications of the internal structure and crystal fabrics of the West Antarctic ice sheet as revealed by deep core drilling at Byrd Station. Geol. Soc. Am. Bull., $87(12), 1665-1677$.

Gow, A.J., D.A. Meese, R.B. Alley and J.J. FitzPatrick. 1993. Crystalline structure and c-axis fabrics of the GISP2 core from surface to bedrock. EOS, 74 (43), Supplement, 89.

Grootes, P. M., M. Stuiver, J. W. C. White, S. Johnsen and J. Jouzel. 1993. Comparison of oxygen isotope records from the GISP2 and GRIP Greenland ice cores. Nature, 366 6455), $552-554$.

Gross, G. W., I. C. Hayslip and R. N. Hoy. 1978. Electrical conductivity and relaxation in ice crystals with known impurity content. $\mathcal{f}$. Glaciol., 2185 ), 143-160.

Jouzel, J. and 6 others. 1987. Vostok ice core: a continuous isotope temperature record over the last climatic cycle $(160,000$ years $)$. Nature, 329 (6138), 403-408.

Langway, C. C., Jr, H. Shoji and N. Azuma. 1988. Crystal size and orientation patterns in the Wisconsin-age ice from Dye 3, Greenland. Ann. Glaciol., 10, $109-115$.

Legrand, M., M. De Angelis, T. Staffelbach, A. Neftel and B. Stauffer. 1992. Large perturbations of ammonium and organic acids content in the Summit-Greenland ice core: fingerprint from forest fires? Geophys. Res. Letl., 19 (5), 473-475. 
Mayewski, P. A. and 7 others. 1993. The atmosphere during the Younger Dryas. Science, 261(5118), 195-197.

Meese, D.A. and 8 others. 1994. The accumulation record from the GISP2 core as an indicator of climate change throughout the Holocene. Science, 266 (5191), 1680-1682.

Paterson, W. S. B. 1991. Why ice-age ice is sometimes "soft". Cold Reg. Sci. Technol., 20 (1), 75-98.

Petit, J. R., P. Duval and C. Lorius. 1987. Long-term climatic changes indicated by crystal growth in polar ice. Nature, 326 6108), 6264.

Petit, J. R., P. Duval and C. Lorius. 1988. Scientific correspondence. Longterm climate changes from crystal growth. Nature, 332 (6165), 593.

Taylor, K. C., P. A. Mayewski, M. S. Twickler and S. I. Whitlow. 1996. Biomass burning recorded in the GISP2 ice core: a record from eastern Canada? Holocene, 6(1), 1-6.

Thorsteinsson, Th., J. Kipfstuhl, H. Eicken, S.J. Johnsen and K. Fuhrer. 1995. Crystal size variations in Eemian-age ice from the
GRIP ice core, central Greenland. Earth Planet. Sci. Lett., 131(3-4), 381-394.

Underwood, E. E. 1970. Quantitative stereology. Reading, MA, AddisonWesley Publishing Co.

Whitlow, S., P. Mayewski, J. Dibb, G. Holdsworth and M. Twickler. 1994. An ice-core-based record of biomass burning in the Arctic and subarctic, 1750-1980. Tellus, 46B 3), 234-242.

Wolff, E. W. 1996. Location, movement and reactions of impurities in solid ice. In Wolff, E. W. and R. Bales, eds. Chemical exchange between the atmosphere and polar snow. Berlin, etc., Springer-Verlag. (NATO ASI Series.) I (43), 541-565.

Wolff, E. W., R. Mulvaney and K. Oates. 1988. The location of impurities in Antarctic ice. Ann. Glaciol., 11, 194197.

Woods, G.A. 1994. Grain growth behavior of the GISP2 ice core from central Greenland. University Park, PA, Pennsylvania State University. Earth System Science Center. (Technical Report 94-002.) 